\title{
Attraction as a function of similarity of perceptual judgments*
}

\author{
ANDREW P. SCHETTINO $\dagger$ and WILLA B. BALDWIN $\dagger \dagger$ \\ Purdue University, West Lafayette, Indiana 47907
}

\begin{abstract}
The aim of the present study was to establish a relationship between similarity and attraction using task performance as the stimulus variable. Sixty-four Ss performed a perceptual task involving 20 trials. Attraction toward a partner was greater when the partner's perceptual judgments were similar to the $S$ 's than when they were dissimilar $(\mathrm{p}<.007)$. The findings thus extend Byrne's "attraction paradigm" to include task performance as a stimulus variable.
\end{abstract}

Byrne (1971) has initiated a body of research in the area of interpersonal attraction within what he describes as the "attraction paradigm." Byrne and Clore (1970) have proposed a model for the formation of attraction responses which utilizes reinforcement concepts. A great deal of research has been carried out using attitudes as the stimulus variable. Consistently, the manipulation of attitude similarity-dissimilarity between a $S$ and a supposed stranger yields a linear relationship with the attraction response.

Attitudes may be viewed as perceptions about the "real world." Although most of us may feel that our attitudes are correct and that attitudes which differ from ours are incorrect, attitudes are, of course, subjectively based. Festinger (1954) has proposed a theory of social comparison which is based on the following hypothesis: "There exists, in the human organism, a drive to evaluate his opinions and his abilities [p. 117]." Of specific importance to the present study is the following hypothesis: "To the extent that objective, non-social means are not available, people evaluate their opinions and abilities by comparison respectively with the opinions and abilities of others [Festinger, 1954, p. 118]."

Festinger points out that a great advantage of this theory is that it predicts that in a social comparison situation, "... one can work back and forth between opinions and ability evaluations [p. 138]." If this proposition is correct, similarity-dissimilarity of perceptual judgments should have the same effects on interpersonal attraction as does similarity-dissimilarity of attitudes. Also, these effects should be greater to the extent that the $\mathrm{S}$ lacks confidence in his own perceptual judgments.

A study by Senn (1971) has attempted to apply Festinger's social comparison theory to interpersonal attraction research. Senn reports that the "findings supported Byrne's 'law of attraction' and extended the

*This research was supported in part by Research Grant GS-40339 from the National Science Foundation, Donn Byrne, principal investigator. This papex is sponsored by Donn Byrne, who takes full editorial respondibility for its contents.

†R equests for reprints should be sent to Andrew P. Schettino,

Department of Psychological Sciences, Purdue University, West Lafayette, Indiana 47907.

++ Now at the University of Texas, Austin, Texas 78712. generality of the similarity-attraction relationship to task-performance behavior." Because the Senn study manipulated not only similarity of task performance but also success or failure for the $\mathrm{S}$, this combination of variables makes it unclear as to whether performance similarity alone affects attraction. The purpose of the present study was to determine whether that variable influences interpersonal attraction in the same fashion as does attitude similarity. Specifically, this study attempted to extend Byrne's attraction paradigm by establishing a relationship between similarity and attraction using a perceptual task as the stimulus variable. The following hypothesis was tested: attraction toward a stranger is a positive linear function of the proportion of similar perceptual judgments.

\section{METHOD}

\section{Subjects}

The Ss were 64 volunteers ( 35 males and 29 females) drawn from the $S$ pool in introductory psychology at Purdue University. All Ss received credit toward their course requirement of research participation. The Ss were randomly assigned to the eight experimental conditions, with approximately equal numbers of males and females in each group.

\section{Apparatus}

The perceptual task was a video taped series of 20 slides projected on a viewing screen. Each slide consisted of a white background and from 5 to 10 black dots. The Ss were run in individual cubicles. Each cubicle had a video monitor, a six-button response panel, and a headset for two-way audio communications.

\section{Design}

The design of the study was a 2 by 2 by 2 factorial with three between-S factors: manipulated similarity of perceptual judgments, manipulated degree of certainty, and the presence or absence of attitudinal information about the other person.

The manipulations for the two levels of similarity of perceptual judgments were: (1) high similarity-the partner's responses were presented such that 14 were identical to the S's, 4 were one away, and 2 were two away; (2) low similarity-the partner's responses were presented such that 14 were two away from the $S$ 's, 4 were one away, and 2 were identical.

The dot patterns were shown at two shutter speeds to manipulate the dgree to which the $S$ was certain of his responses. For the high-certainty condition, a shutter speed of $1.0 \mathrm{sec}$ was 
Table 1

Mean Attraction Responses Toward Strangers With Similar or Dissimilar Perceptual Judgments by Subjects High or Low in Certainty With or Without Additional Attitude Information

Perceptual Judgments

\begin{tabular}{cccccc}
\cline { 5 - 6 } & \multicolumn{2}{c}{ Similar } & & \multicolumn{2}{c}{ Dissimilar } \\
\cline { 2 - 3 } \cline { 5 - 6 } Certainty & Attitudes & $\begin{array}{c}\text { No } \\
\text { Attitudes }\end{array}$ & & Attitudes & $\begin{array}{c}\text { No } \\
\text { Attitudes }\end{array}$ \\
\hline High & 10.63 & 10.13 & & 9.13 & 9.88 \\
Low & 10.13 & 10.13 & & 8.88 & 7.75 \\
\hline
\end{tabular}

used. For the low-certainty condition, a shutter speed of $0.02 \mathrm{sec}$ was used.

The Ss who received the attitude information were given a 6-item survey of attitudes. This survey was described as additional information and was supposedly filled out by the partner. (All Ss completed a 12-item survey at the start of the semester.) The 6-item survey contained three attitudes similar to the S's and three dissimilar.

\section{Dependent Variables}

Attraction was measured by a modified version of the interpersonal judgment scale (Byrne, 1971). The Ss made evaluative responses on a 7-point scale for each of five items, and the attraction measure was the sum of the last two items (liking and desirability as a work partner). The first three items called for evaluations of the partner's willingness to perform the perceptual task, intelligence, and adjustment.

Affect was measured by a semantic differential scale. Six scales from Osgood's semantic differential (Osgood, Suci, \& Tannenbaum, 1957) were used, following the procedure suggested by Byrne and Clore (1970). The Ss made affective responses on a 7-point scale for each item. The sum of the responses to the six items made up the affect score. The six items called for evaluations of the S's feelings (comfortable-uncomfortable, good-bad, high-low, happy-sad, pleasant-unpleasant, and positive-negative).

\section{Procedure}

Ss signed up for what had been described as an experiment in visual perception. Upon arrival, the Ss were placed in the individual cubicles. Each $\mathrm{S}$ was told that his partner had already arrived.

In the first set of instructions, the $\mathrm{S}$ was reminded that the experiment concerned visual perception. He was told that the first part of the experiment would consist of a series of 20 trials. On each trial, the $\mathrm{S}$ was to press the button that corresponded to the number of dots he saw. The $S$ was told that he had been paired with a partner and that he would see his partner's response af ter he had responded. During the perceptual task, the E provided programmed feedback to each $S$.

After the perceptual task, one of two sets of video-taped instructions were shown. Ss receiving the attitude information were told that they were being given additional information about their partner. Ss not receiving the attitude information performed on interpolated activity. They were told to look over a blank six-item survey of attitudes and rank how important each topic was to them.

Next, the S was told that one purpose of the experiment was to see what kinds of impressions Ss formed of each other in an experimental situation. In counterbalanced order, the $\mathrm{S}$ was asked to fill out the interpersonal judgment scale and a postperceptual task questionnaire intended to measure how certain the $S$ was of his responses. Next, the $S$ was given a semantic differential scale. And finally, each $\mathrm{S}$ was debriefed and dismissed.

\section{RESULTS}

The evaluative responses to the IJS were analyzed using a three-way between-groups analysis of variance. ${ }^{1}$ The mean attraction ratings for each of the eight experimental conditions are presented in Table 1. Only the main effect for similarity of perceptual judgments was significant $(F=8.05, \mathrm{df}=1 / 63, \mathrm{p}<.007)$. Separate analyses of the two attraction items revealed that the effect was significant only with respect to desirability as a work partner $(\mathrm{F}=12.01, \mathrm{df}=1 / 63, \mathrm{p}<.002)$ and not with respect to liking $(F=2.72$, $d f=1 / 63, p=.10)$. Although the certainty manipulation had no effect on attraction, the Ss' perceived certainty was significantly influenced by the manipulation. ${ }^{2}$ Each of the other three IJS items was also analyzed separately. Similar partners were seen as more willing to perform the perceptual task $(\mathrm{HS}=6.06, \mathrm{LS}=5.47, \mathrm{~F}=6.09, \mathrm{df}=$ $1 / 63, \mathrm{p}<.02)$ and more intelligent $(\mathrm{HS}=5.03, \mathrm{LS}=$ $4.56, \mathrm{~F}=5.16, \mathrm{df}=1 / 63, \mathrm{p}<.03)$ than dissimilar partners. There was no effect for the adjustment item $(F$ $=2.11$ ).

The two attraction items were also analyzed using a three-way between-within groups analysis of variance. ${ }^{3}$ Similarity of perceptual judgments and the presence or absence of attitudinal information about the partner were the between factors. Only the main within effect approached significance (liking $=4.89$, work partner $=$ 4.67, $F=3.06, d f=1 / 60, p=.08)$.

A Pearson product moment correlation coefficient was computed for the correlation of the attraction response from the IJS with the affective response from the semantic differential scale. The correlation was marginally significant $(\mathrm{r}=.21, \mathrm{p}=.06)$. The computation of separate correlation coefficients for the two attraction items revealed that the correlation was significant only for desirability as a work partner $(r=$ $.24, \mathrm{p}=.03)$, and not for liking $(\mathrm{r}=.13, \mathrm{p}=.16)$.

\section{DISCUSSION}

These results support the contention that similarity of perceptual judgments has the same effect on interpersonal attraction as does attitude similarity. However, it should be noted that similarity of task performance affected only one of the two attraction items on the IJS to a significant degree. Consistent with this result, only one of the attraction items was significantly correlated with the affective response from the semantic differential scale. Whether these results represent a general distinction between attitudes and task performance or were caused by some specific aspect of the present study will have to be determined by subsequent research.

Two conclusions appear to be warranted from the data of this study. First, similarity of task performance had a positive effect on attraction. It is therefore proposed that the attraction paradigm can be extended to include similarity of task performance as a stimulus variable. Second, based on the interpretation of the results described above, it appears obvious that subsequent research should be designed to clarify the 
task-specific influence of similarity on different attraction responses.

\section{REFERENCES}

Byrne, D. The attraction paradigm. New York: Academic Press, 1971.

Byrne, D., \& Clore, G. L. A reinforcement model of evaluative responses. Personality: An International Journal, 1970, 1, 103-128.

Festinger, L. A theory of social comparison processes. Human Relations, 1954, 7, 117-140.

Osgood, C., Suci, G., \& Tannenbaum, P. The measurement of meaning. Urbana, Iilinois: University of Illinois Press, 1957.

Senn, D. Attraction as a function of similarity-dissimilarity in task performance. Journal of Personality \& Social Psychology, 1971, 18, 120-123.

\section{NOTES}

1. An initial four-way between groups analysis of variance indicated that there were no significant effects for the sex of the S.

2. The Ss in the high-certainty (HC) conditions were more sure of their perceptual judgments than Ss in the low-certainty (LC) conditions. This was expressed on the postperceptual task questionnaire in answer to the question "How many of your responses do you feel were correct?" $(\mathrm{HC}=14.47, \mathrm{LC}=11.33$, $\mathrm{F}=13.63$, df $=1 / 63, \mathrm{p}<.001)$.

3. An initial five-way between-within groups analysis of variance indicated that there were no significant effects for the sex of the $S$ and for the certainty manipulation.

(Received for publication February 16, 1974.)

\title{
Cutaneous perception of heroin addicts: Evidence of an altered temporal process*
}

\author{
ROBERT J. HALL and MARJORIE A. ROSENBERGER \\ EG\&G, Inc., Special Projects Division, 3084B South Highland Avenue, Las Vegas, Nevada 89109 \\ and \\ RICHARD A. MONTY† \\ Human Engineering Laboratory, Aberdeen Proving Ground, Maryland 21005
}

\begin{abstract}
The time taken to detect the direction of movement of a stylus drawn across the volar surface of the forearm is greater for heroin addicts than for nonaddicts. The slower the speed of movement of the stylus, the greater the difference. Perception of nontemporally related dimensions is not affected, indicating that the effects of heroin appear to be highly specific, and alter the central nervous system's temporal processes which govern and regulate excitability cycles and cortical scanning.
\end{abstract}

Several recent studies have suggested that there may be fundamental changes in the sensory behavior of drug users and addicts. For example, Smith (1972) reported

* This study was sponsored by the Advanced Research Projects Agency under ARPA Order No. 2128.

tRequests for reprints should be sent to Richard A. Monty, Behavioral Research Directorate, U.S. Army Human Engineering Lab, Aberdeen Proving Ground, Maryland 21005. that the taste thresholds of addicts for quinine were significantly lower than those of controls and alcoholics. Similarly, a recent series of studies of the visual behavior of drug addicts (Hall, Rosenberger, \& Monty, 1973) indicated that there were basic differences between addicts and controls in the rapid eye movement associated with fixation sequences and that these may indicate disturbance of the temporal processes which 